Review

\title{
Analysis of laser therapy and assessment methods in the rehabilitation of temporomandibular disorder: a systematic review of the literature
}

\author{
Carolina Marciela Herpich ${ }^{1)^{*}}$, Ana Paula Amaral ${ }^{1)}$, Ernesto Cesar Pinto Leal-Junior ${ }^{2)}$, \\ Juliana de Paiva Tosato ${ }^{3)}$, Cid Andre Fidelis de Paula Gomes ${ }^{4}$, Ékic Edmur Camargo Arruda ${ }^{1)}$, \\ Igor Phillip dos Santos Glória ${ }^{1)}$, Marilia Barbosa Santos Garcia ${ }^{1)}$, \\ Bruno Roberto Borges Barbosa ${ }^{1)}$, Monique Sampaio Rodrigues ${ }^{4)}$, Katiane Lima Silva ${ }^{4}$, \\ Yasmin El Hage ${ }^{5}$ ), Fabiano Politti ${ }^{5)}$, Tabajara de Oliveira Gonzalez ${ }^{6}$, \\ Sandra Kalil Bussadori ${ }^{1)}$, Daniela Aparecida Biasotto-GonZalez ${ }^{1}$ ) \\ 1) Postgraduate Program in Rehabilitation Sciences, Movement Analysis Research Support Center, \\ University Nove de Julho (UNINOVE): Rua Profa Maria Jose Barone Fernandes, 300, Sao Paulo, \\ SP, 02117-020, Brazil \\ 2) Postgraduate Program in Rehabilitation Sciences, Laboratory of Phototherapy in Sports and \\ Exercise, University Nove de Julho (UNINOVE), Brazil \\ 3) Postgraduate Program in Biophotonics Applied to Health Sciences, University Nove de Julho \\ (UNINOVE), Brazil \\ 4) Graduation Phisical Therapy, Universidade Nove de Julho (UNINOVE), Brazil \\ 5) Program in Rehabilitation Sciences, Movement Analysis Research Support Center, University Nove \\ de Julho (UNINOVE), Brazil \\ 6) Department of Physical Therapy Universidade Nove de Julho (UNINOVE), Brazil
}

\begin{abstract}
The aim of the present study was to perform a systematic review of the literature on the effects of low-level laser therapy in the treatment of TMD, and to analyze the use of different assessment tools. [Subjects and Methods] Searches were carried out of the BIREME, MEDLINE, PubMed and SciELO electronic databases by two independent researchers for papers published in English and Portuguese using the terms: "temporomandibular joint laser therapy" and "TMJ laser treatment". [Results] Following the application of the eligibility criteria, 11 papers were selected for in-depth analysis. The papers analyzed exhibited considerable methodological differences, especially with regard to the number of sessions, anatomic site and duration of low-level laser therapy irradiation, as well as irradiation parameters, diagnostic criteria and assessment tools. [Conclusion] Further studies are needed, especially randomized clinical trials, to establish the exact dose and ideal parameters for low-level laser therapy and define the best assessment tools in this promising field of research that may benefit individuals with signs and symptoms of TMD.

Key words: Temporomandibular joint disorder, Electromyography, Laser
\end{abstract}

(This article was submitted May 21, 2014, and was accepted Jul. 18, 2014)

\section{INTRODUCTION}

Temporomandibular (TMD) disorder refers to a set of clinical conditions involving the masticatory muscles, temporomandibular joint (TMJ) and associated structures ${ }^{1)}$. Pain is one of the most common and limiting clinical manifestations of this disorder ${ }^{2-4)}$ and can compromise quality of life ${ }^{5,6)}$, sleep ${ }^{7,8)}$, and psychological aspects, leading to anxiety, stress and even depression. The multifactor etiology

*Corresponding author. Carolina Marciela Herpich (E-mail: carolinaherpich12@hotmail.com)

(인 2015 The Society of Physical Therapy Science. Published by IPEC Inc. This is an open-access article distributed under the terms of the Creative Commons Attribution Non-Commercial No Derivatives (by-ncnd) License $<$ http://creativecommons.org/licenses/by-nc-nd/3.0/> . of TMD requires a multidisciplinary team of health professionals ${ }^{9)}$, including a physiotherapist. A number of studies have addressed physical therapy modalities for the treatment of TMD, such as electrotherapy ${ }^{10,11)}$, laser therapy ${ }^{12,13)}$ and manual therapy ${ }^{14-16)}$.

Low-level laser therapy (LLLT) has been widely used in the health field for therapeutic purposes and biostimulation, due to its characteristics of low-intensity energy, and wavelengths capable of penetrating tissues and exerting an influence on the synthesis, release and metabolism of numerous signaling substances involved in analgesia ${ }^{17,18)}$. Besides these neuro-pharmacological effects, there is evidence that LLLT leads to reductions in the inflammatory process, Cfiber activity, and the excitability of the nervous system, as well as an increase in blood circulation ${ }^{19,20)}$.

The present systematic review of the literature was motivated by the wide diversity of information on LLLT in the 
treatment of TMDs, the variety of application parameters and the different assessment tools used in different studies. Systematic reviews are highly valued studies that provide evidence that can contribute to the establishment of guidelines and enhance the quality of clinical research ${ }^{21}$. The present review was carried out to determine the different types of experimental procedures used to study the effects of LLLT in the treatment of TMD, and distinguish which studies provide evidence of the benefits of this form of therapy, as well as to identify and analyze the different assessment tools employed, to offer health professionals in this field a better understanding of the technique.

\section{SUBJECTS AND METHODS}

Searches were carried out of the BIREME, MEDLINE, PubMed and SciELO electronic databases by two independent researchers for papers published in English and Portuguese during the period from 2008 to 2013. The searches began on October 1st and ended on December 20th, 2013. The search terms used were "temporomandibular joint laser therapy" and "TMJ laser treatment". An overview of the systematic review process is presented in Fig. 1.

\section{Methods}

Clinical trials published between 2008 and 2013 that investigated the effect of LLLT in the treatment of TMD were included in this review. Thus, the findings of the most recent studies are presented, taking into consideration the use of LLLT in clinical practice and different evaluation methods. Each study needed to describe the type of laser, application time, administration parameters and assessment tools in order to allow the identification of the different protocols and compare the respective findings. Papers that failed to meet these criteria and reviews of the literature were excluded from the initial analysis (Fig. 1).

The Physiotherapy Evidence Database (PEDro) scale, which is based on the Delphi list, was used to evaluate the methodological quality of the papers. Articles with higher levels of clinical evidence were selected using this scale, the reliability of which has been empirically supported. A total score of up to 10 points was attributed to each paper based on the total number of criteria met ${ }^{22}$.

Two researchers who had undergone training in the use of the PEDro scale performed the reading and scoring of the papers. Neither researcher had knowledge of the scores given by the other. Agreement between the two researchers was then analyzed. In cases of disagreement, the papers were read again and the final score was determined by consensus.

A plus symbol $(+)$ was placed on the chart for every criterion met and a minus symbol $(-)$ was used when a criterion was not met. A question mark (?) indicated the non-scoring of a criterion due to a lack of certainty regarding whether the criterion was met. The final score was determined by summing the number of criteria met, excluding the first criterion, which is not considered in the scoring process. Papers with a final score of 4 or more points were placed in tables with descriptions of their respective variables analyzed and outcomes.

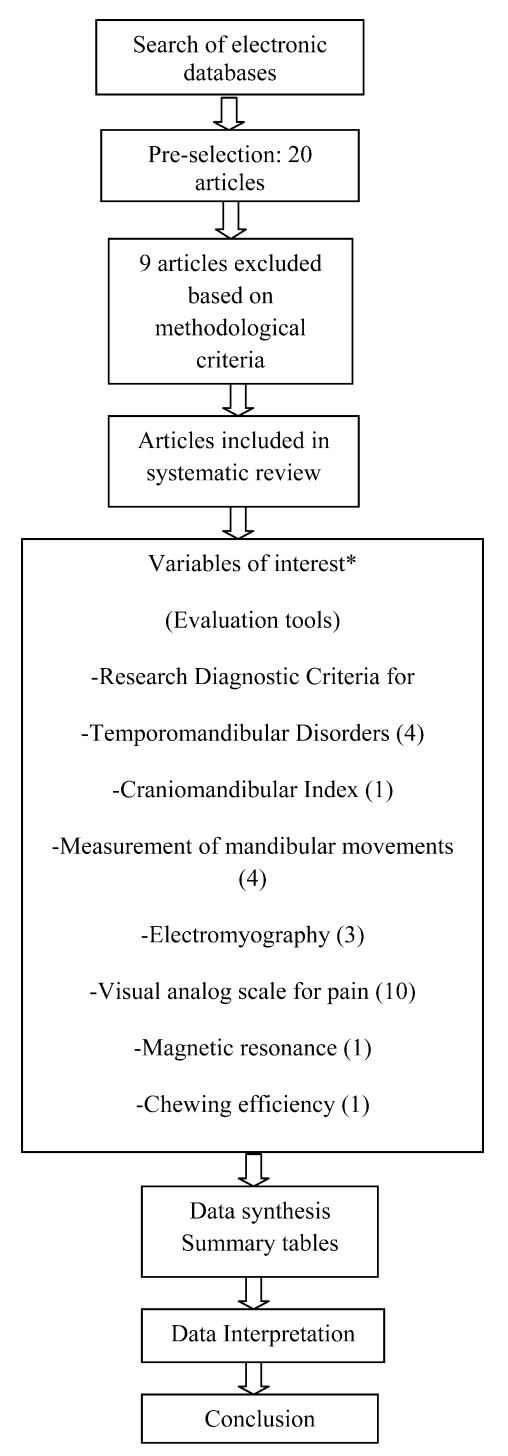

Fig. 1. Articles included in this review *The sum of articles in each category totals more than the number of articles included in the review due to the fact that some studies reported more than one outcome.

\section{RESULTS}

After the search of BIREME, MEDLINE, PubMed and SciELO electronic databases and the application of the eligibility criteria, 11 studies were selected for analysis (Tables 1 and 2). Graph 1 shows the scores for each role in the PEDro scale. The scores range from 4 to 7 points.

A number of assessment tools are described in the literature for the evaluation of TMD, including questionnaires ${ }^{23)}$, patient history indices ${ }^{24,25)}$, clinical indices ${ }^{24,26,27)}$, and diagnostic criteria ${ }^{2,28)}$. Each assessment tool has advantages, disadvantages, and limitations, as well as distinct applicability. Thus, clinicians and researchers need to be aware of the data obtained using each tool in order to employ it properly. Surface electromyography (EMG) is a valuable method for the characterization and diagnosis of individuals with 
orofacial and occlusal abnormalities ${ }^{29}$. This noninvasive tool allows the objective determination of muscle activity through electric signals with the muscle at rest or during contraction. In the investigation of TMD, surface EMG has been mainly used to evaluate the temporal and masseter muscles ${ }^{30)}$. Moreover, a number of reliable tools are available for the quantification of pain intensity, such as the visual analog scale (VAS), which allows the comparison of subjective pain intensity, and monitoring the effects of treatment. An algometer is another tool used in the semi-quantitative measurement of pain that allows locating trigger points and quantifying changes in different pain syndromes.

Venezian et al. ${ }^{31)}$ used the Research Diagnostic Criteria for Temporomandibular Disorders (RDC/TMD), and both the VAS and electromyography to perform evaluations prior to treatment, immediately after, and 30 days after LLLT. The authors found no significant difference in EMG activity before and after treatment. Hotta et al. ${ }^{32)}$ also used EMG and found statistically significant improvements $(p<0.01)$ in both pain and activity of the masseter muscle in habitual occlusion following LLLT, but no significant improvement in mandibular movements using points employed in orofacial acupuncture. In contrast, Venezian et al. ${ }^{31)}$ used three points on the masseter and one point on the temporal muscle, and Shinozaki et al. ${ }^{33)}$ applied LLLT over the TMJ, region of the auriculotemporal nerve and masseter muscle in a single session. Both groups of researchers found a reduction in EMG activities of the masseter and temporal muscles.

Shirani et al. ${ }^{34)}$, Emshoff et al. ${ }^{35)}$ and Carvalho et al. ${ }^{36)}$ only used the VAS in the evaluation and found a reduction in pain. However, the reduction was not significant in the study by Emshoff et al. ${ }^{35)}$, who performed evaluations at baseline and after two, four and eight weeks covering a total of 20 treatment sessions. However, it should be pointed out that the LLLT was applied at a distance of $1 \mathrm{~cm}$ over the TMJ, differing from the other authors cited, who used trigger points of the masticatory muscles. Salmos-Brito et al. ${ }^{37)}$ also used trigger points around the TMJ, employing the RDC/ TMD for diagnosis and the VAS and a digital ruler for the evaluations, which is useful for the measurement of range of motion, and found significant differences in pain intensity and maximum mouth opening after treatment.

Da Cunha et al. ${ }^{38)}$ employed the craniomandibular index and the VAS for evaluation and found a significant reduction in pain following treatment in both groups when using the VAS ( $\mathrm{p}<0.05$ ), but no significant differences in pain or symptoms of TMD when using the craniomandibular index. This index was developed by Fricton et al. ${ }^{26)}$ to allow the evaluation of signs and symptoms of TMD with greater precision. Frare et al. ${ }^{39)}$ used different evaluations in the selection of cases, comparing a clinical evaluation using a chart based on Okeson, the screening questionnaire recommended by the American Academy of Orofacial Pain, and the VAS. Carrasco et al. $^{40)}$ employed the VAS and a colorimetric method involving the chewing of a capsule, and found that laser therapy led to a reduction in pain as well as enhanced chewing efficiency.

The LLLT application site was the treatment condition that most differed among the studies. LLLT was applied to the TMJ in five studies ${ }^{17,35,37,39,40)}$, the masticatory muscles in three studies ${ }^{31,34)}$, both the TMJ and masticatory muscles in three studies $\left.{ }^{33}, 36,38\right)$, and the points employed in acupuncture in one study ${ }^{32}$. Among the studies in which LLLT was applied to the TMJ, some papers reported positive results in comparison to a placebo group. Among the studies in which LLLT was applied to the masticatory muscles, two papers reported positive results ${ }^{34,38)}$. However, Venezian et al. ${ }^{31)}$, who used three points on the masseter and one point on the temporal muscle, found a significant difference in VAS scores, but not in EMG. In a study of LLLT for both the TMJ and masticatory muscles, significant reductions were found in both pain and EMG activity after a single session ${ }^{33)}$. The study by Emshoff et al. ${ }^{35)}$, which received one of the highest PEDro scores from both assessors due to its excellent methodology, found a similar pain reduction effects in the laser therapy and placebo groups following LLLT over the TMJ, but the reduction in pain was not significant, which is in disagreement with results reported in other studies.

The number of applications differed considerably among the studies, ranging from a single application to 20 applications ( 2 to 3 application per week over 8 weeks). Emshoff et al. ${ }^{35)}$ employed the greatest number of sessions, and found a reduction in pain in the TMJ during jaw function, but there was no significant difference between the LLLT and placebo groups. Shinozaki et al. ${ }^{33)}$ employed a single session on the masticatory muscles and found a significant reduction in EMG activity in the masseter and temporal muscles.

The duration of each application varied from 16 seconds $^{39}$ ) to 20 seconds $^{31,32,38)}$ and as much as 10 minutes $^{17,34)}$. Based on the findings of these studies, it seems that an increase in duration does not lead to enhanced effectiveness when the LLLT is applied to the TMJ. However, positive results were achieved when the LLLT was applied to the masticatory muscles for 360 seconds or more. Moreover, the findings demonstrate that while positive results were reported after a single session, no study has demonstrated how long the effects of a single session last. In a study involving eight sessions of LLLT, Venezian et al. ${ }^{31)}$ reported that the reduction in pain was maintained 30 days after the end of treatment.

Pain was assessed using the VAS, the number of trigger points or the craniomandibular index. Jaw function was assessed through the measure of maximum mouth opening, protrusion and lateral mandibular movements, joint sounds, chewing efficiency and muscle activity (EMG). Investigating the correlation between mandibular range of motion and pain, Salmos-Brito et al. ${ }^{37)}$ and Marini et al. ${ }^{17)}$ found improvements in both variables following treatment. Carrasco et al. ${ }^{40)}$ found enhanced chewing efficiency and a greater reduction in pain in comparison to a placebo group. These findings indicate that pain intensity exerts a direct influence on jaw function. Further studies are needed on the treatment of TMD, as pain is the main symptom of this dis$\operatorname{order}^{10,11,15,16)}$. Moreover, muscle and/or joint impairment is prevalent among affected individuals ${ }^{41)}$, which can have a significant impact on quality of life and activities of daily living, such as eating, speaking, yawning and smiling ${ }^{42)}$.

The literature offers a wide variety of tools for the diagnosis and evaluation of TMD. The tool of choice should be based on a grounded judgment and the specific intentions of the researcher or clinician. The studies analyzed herein 


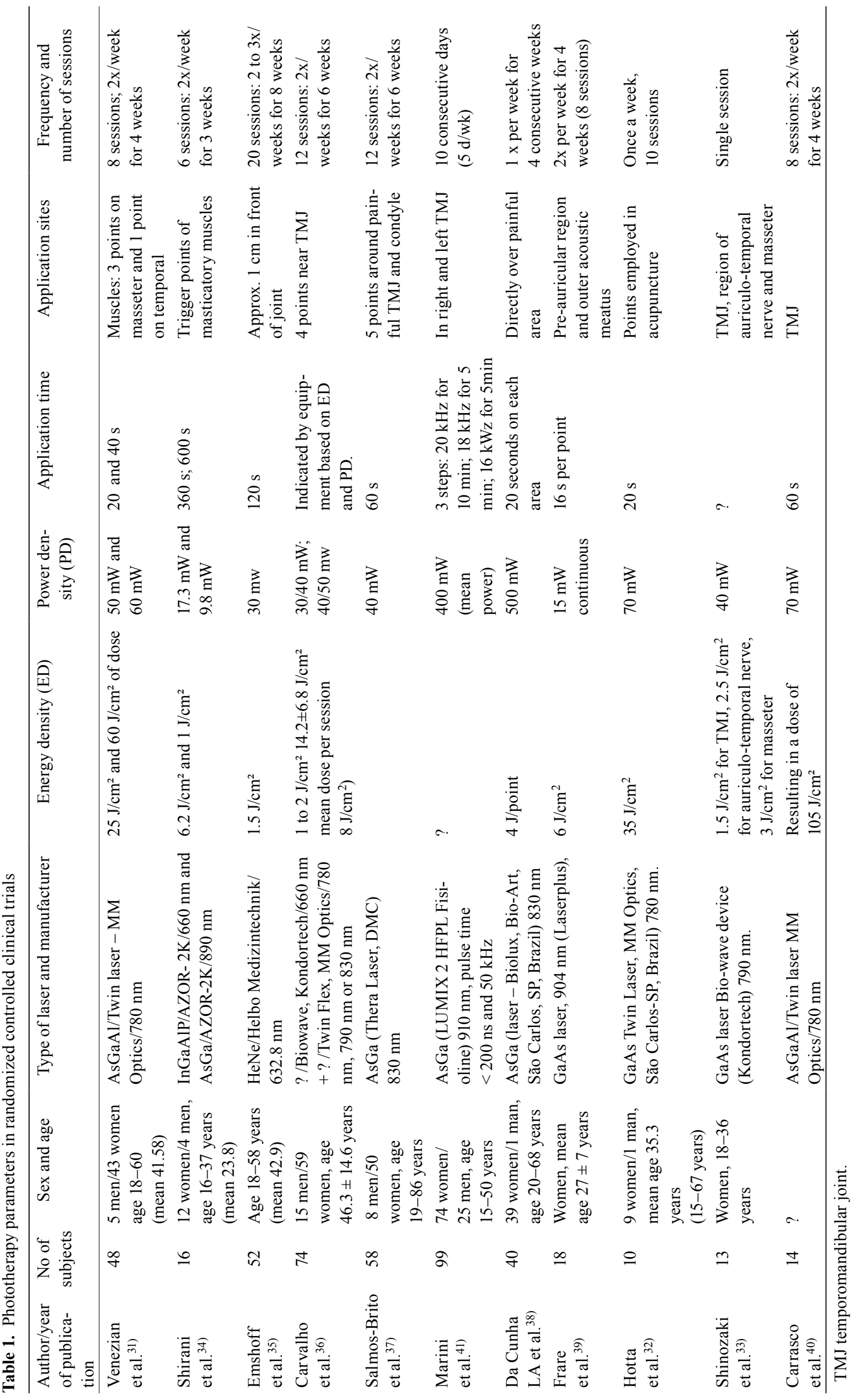




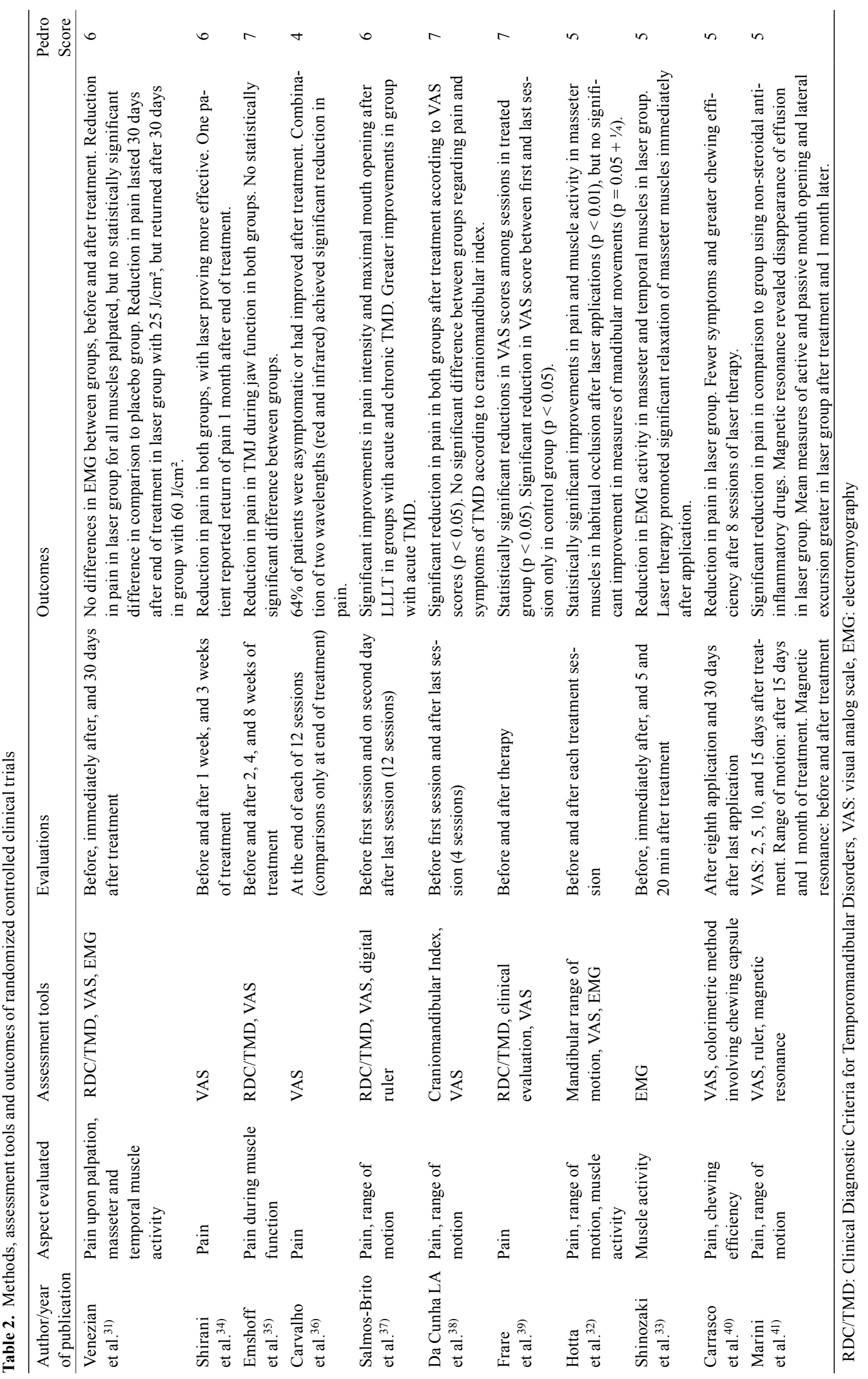


demonstrate the importance of a more objective evaluation involving EMG, magnetic resonance imaging, the measure of mandibular range of motion, etc., as well as other evaluations regarding the efficacy of treatment with the use of the VAS to enhance the credibility of LLLT treatment and guide clinical conduct.

\section{DISCUSSION}

As a disorder with a multifactor etiology, a number of modalities have been proposed for the treatment of signs and symptoms of TMD, such as bite plate usage, acupuncture, kinesiology, massage therapy, joint manipulation, drug therapy and LLLT $^{11}$ 15, 16,31, 43). LLLT has been studied since 1905, when Albert Einstein proposed the theory of stimulated emission. In 1960, this became reality with the first emitter (ruby), developed by Theodore Maiman ${ }^{44)}$, and emitted a light with coherence, monochromaticity and a low degree of divergence.

According to Pinto et al. ${ }^{45}$ ), LLLT is comprised of electromagnetic waves (either visible or invisible) of low intensity energy and wavelengths capable of penetrating tissues and influencing the synthesis, release and metabolism of numerous signaling substances involved in analgesia ${ }^{17,18)}$. Since the publication of the first randomized clinical trial investigating the effects of LLLT on rheumatoid arthritis in the $1980 \mathrm{~s}^{46)}$, a number of positive effects have been reported in studies involving other musculoskeletal disorders. Despite the lack of clear scientific evidence regarding the action mechanisms of LLLT ${ }^{47}, 48$, theories have been put forth to explain the therapeutic effects capable of altering cell functions, such as reduction in bradykinin expression, edema, pain substances and inflammation time as well as increases in beta-endorphins and blood flow, the release of histamine and the promotion of muscle relaxation ${ }^{35,37)}$.

In the interpretation of the data, discrepancies are evident in the administration parameters, number of sessions, and application sites of LLLT. A wide array of diagnostic and assessment tools for TMD is described in the literature. The choice of the most appropriate tool should be based on the specific objectives of the researcher or clinician. However, the literature offers little evidence of local and systemic analgesia following the administration of LLLT using pressure algometry as the evaluation tool ${ }^{49)}$.

The complexity of LLLT in the treatment of TMD and the lack of methodological quality in the clinical trials analyzed limits the indication of this physiotherapeutic modality $^{17,31-40)}$. Thus, further investigations with an good study design and adequate methodology (better control of the variables and the assurance of reproducibility) are needed to identify the benefits of LLLT in the treatment of TMD.

LLLT is effective in the treatment of TMD, especially in the reduction of muscle pain. However, there is an evident lack of standardization in the parameters employed, which limits our ability to draw more definitive conclusions. The visual analog scale for pain and a clinical evaluation are the most widely used tools for the assessment of the effects of LLLT. Further studies are needed, especially randomized clinical trials, to establish the exact dose and ideal parameters for LLLT, and to define the best assessment tools in this promising field of therapy that appears to offer many benefits to individuals with signs and symptoms of TMD.

\section{Conflict of competing interests}

Professor Ernesto Cesar Pinto Leal-Junior receives research support from Multi Radiance Medical (Solon, OH, USA), a laser device manufacturer. Multi Radiance Medical had no role in the planning, study design, data collection and analysis, the decision to publish, or the preparation of this manuscript. The remaining authors declare that they have no conflict of interest.

\section{REFERENCES}

1) De Leeuw R: Orofacial pain: guidelines for assessment, diagnosis and management, 4th ed. The American Academy of Orofacial Pain. Chicago: Quintessence, 2008 .

2) Truelove EL, Sommers EE, LeResche L, et al.: Clinical diagnostic criteria for TMD. New classification permits multiple diagnoses. J Am Dent Assoc, 1992, 123: 47-54. [Medline]

3) Orlando B, Manfredini D, Bosco M: Efficacy of physical therapy in the treatment of masticatory myofascial pain: a literature review. Minerva Stomatol, 2006, 55: 355-366. [Medline]

4) Gonçalves DA, Dal Fabbro AL, Campos JA, et al.: Symptoms of temporomandibular disorders in the population: an epidemiological study. J Orofac Pain, 2010, 24: 270-278. [Medline]

5) Moreno BG, Maluf SA, Marques AP, et al.: Clinical and quality-of-life assessment among women with temporomandibular disorder. Rev Bras Fisioter, 2009, 13: 210-214. [CrossRef]

6) Karacayli U, Mumcu G, Cimilli H, et al.: The effects of chronic pain on oral health related quality of life in patients with anterior disc displacement with reduction. Community Dent Health, 2011, 28: 211-215. [Medline]

7) Yatani H, Studts J, Cordova M, et al.: Comparison of sleep quality and clinical and psychologic characteristics in patients with temporomandibular disorders. J Orofac Pain, 2002, 16: 221-228. [Medline]

8) Smith MT, Wickwire EM, Grace EG, et al.: Sleep disorders and their association with laboratory pain sensitivity in temporomandibular joint disorder. Sleep, 2009, 32: 779-790. [Medline]

9) Issa JP, Silva MA, Silva AM: Disfunções temporomandibulares e suas implicações clínicas. Rev Dor, 2005, 6: 573-578.

10) Rodrigues-Bigaton $\mathrm{D}$, Almeida AF, Berni KC, et al.: Use of different electrical stimulations for treating pain in women with temporomandibular disorders. Braz J Phys Ther, 2008, 12: 476-481. [CrossRef]

11) Gomes NC, Berni-Schwarzenbeck KC, Packer AC, et al.: Effect of cathodal high-voltage electrical stimulation on pain in women with TMD. Rev Bras Fisioter, 2012, 16: 10-15. [Medline] [CrossRef]

12) Bjordal JM, Couppé C, Chow RT, et al.: A systematic review of low level laser therapy with location-specific doses for pain from chronic joint disorders. Aust J Physiother, 2003, 49: 107-116. [Medline] [CrossRef]

13) Rodrigues JH, Biasotto-Gonzalez DA, Bussadori SK, et al.: Signs and symptoms of temporomandibular disorders and their impact on psychosocial status in non-patient university student's population. Physiother Res Int, 2012, 17: 21-28. [Medline] [CrossRef]

14) McNeely ML, Armijo Olivo S, Magee DJ: A systematic review of the effectiveness of physical therapy interventions for temporomandibular disorders. Phys Ther, 2006, 86: 710-725. [Medline]

15) Arruda EE, Amaral AP, Politti F, et al.: Immediate effects of mandibular mobilization on static balance in individuals with temporomandibular disorder pilot study. Clin Exp Med Lett, 2012, 53: 165-169.

16) Amaral AP, Politti F, Hage YE, et al.: Immediate effect of nonspecific mandibular mobilization on postural control in subjects with temporomandibular disorder: a single-blind, randomized, controlled clinical trial. Braz J Phys Ther, 2013, 17: 121-127. [Medline]

17) Marini I, Gatto MR, Bonetti GA: Effects of superpulsed low-level laser therapy on temporomandibular joint pain. Clin J Pain, 2010, 26: 611-616. [Medline] [CrossRef]

18) Andrade TN, Frade JC: Estudo comparativo entre os efeitos de técnicas de terapia manuais isoladas e associadas á laserterapia de baixa potência sobre a dor em pacientes com disfunção temporomandibular. Rev Gaucha Odontol, 2008, 56: 287-295.

19) Reddy GK: Photobiological basis and clinical role of low-intensity lasers in biology and medicine. J Clin Laser Med Surg, 2004, 22: 141-150. [Med- 
line] [CrossRef]

20) Vinck E, Cagnie B, Coorevits $P$, et al.: Pain reduction by infrared lightemitting diode irradiation: a pilot study on experimentally induced delayed-onset muscle soreness in humans. Lasers Med Sci, 2006, 21: 11-18. [Medline] [CrossRef]

21) Marque AP, Peccin MS: Pesquisa em Fisioterapia: a prática baseada em evidências e modelos de estudos. Fisioterapia Pesquisa, 2005, 10: 43-48.

22) Maher CG, Sherrington C, Herbert RD, et al.: Reliability of the PEDro scale for rating quality of randomized controlled trials. Phys Ther, 2003, 83: 713-721. [Medline]

23) Okeson JP: Dor orofacial: guia de avaliação, diagnóstico e tratamento. São Paulo: Quintessence, 1998.

24) Helkimo M: Studies on function and dysfunction of the masticatory system. II. Index for anamnestic and clinical dysfunction and occlusal state. Sven Tandlak Tidskr, 1974, 67: 101-121. [Medline]

25) Fonseca DM, Bonfate G, Valle AL, et al.: Diagnóstico pela anamnese da disfunção craniomandibular. Rev Gaucha Odontol, 1994, 42: 23-28.

26) Fricton JR, Schiffman EL: The craniomandibular index: validity. J Prosthet Dent, 1987, 58: 222-228. [Medline] [CrossRef]

27) Pehling J, Schiffman E, Look J, et al.: Interexaminer reliability and clinical validity of the temporomandibular index: a new outcome measure for temporomandibular disorders. J Orofac Pain, 2002, 16: 296-304. [Medline]

28) Dworkin SF, LeResche L: Research diagnostic criteria for temporomandibular disorders: review, criteria, examinations and specifications, critique. J Craniomandib Disord, 1992, 6: 301-355. [Medline]

29) De Felício CM, Sidequersky FV, Tartaglia GM, et al.: Electromyographic standardized indices in healthy Brazilian young adults and data reproducibility. J Oral Rehabil, 2009, 36: 577-583. [Medline] [CrossRef]

30) Armijo-Olivo S, Gadotti I, Kornerup M, et al.: Quality of reporting masticatory muscle electromyography in 2004: a systematic review. J Oral Sci, 2004, 10: 484-491.

31) Venezian GC, da Silva MA, Mazzetto RG, et al.: Low level laser effects on pain to palpation and electromyographic activity in TMD patients: double-blind, randomized, placebo-controlled study. Cranio, 2010, 28: 84-91. [Medline]

32) Hotta PT, Hotta TH, Bataglion C, et al:: Emg analysis after laser acupuncture in patients with temporomandibular dysfunction (TMD). Implications for practice. Complement Ther Clin Pract, 2010, 16: 158-160 [CrossRef]. [Medline]

33) Shinozaki EB, Dos Santos MB, Okazaki LK, et al.: Clinical assessment of the efficacy of low-level laser therapy on muscle pain in women with temporomandibular dysfunction, by surface electromyography. Braz J Oral Sci, 2010, 9: 434-438.

34) Shirani AM, Gutknecht N, Taghizadeh M, et al.: Low-level laser therapy and myofacial pain dysfunction syndrome: a randomized controlled clinical trial. Lasers Med Sci, 2009, 24: 715-720 [CrossRef]. [Medline]

35) Emshoff R, Bösch R, Pümpel E, et al.: Low-level laser therapy for treatment of temporomandibular joint pain: a double-blind and placebo-con- trolled trial. Oral Surg Oral Med Oral Pathol Oral Radiol Endod, 2008, 105: 452-456. [Medline] [CrossRef]

36) Carvalho CM, de Lacerda JÁ, dos Santos Neto FP, et al.: Wavelength effect in temporomandibular joint pain: a clinical experience. Lasers Med Sci, 2010, 25: 229-232. [Medline] [CrossRef]

37) Salmos-Brito JA, de Menezes RF, Teixeira CE, et al.: Evaluation of lowlevel laser therapy in patients with acute and chronic temporomandibular disorders. Lasers Med Sci, 2013, 28: 57-64. [Medline] [CrossRef]

38) da Cunha LA, Firoozmand LM, da Silva AP, et al.: Efficacy of low-leve laser therapy in the treatment of temporomandibular disorder. Int Dent J, 2008, 58: 213-217. [Medline] [CrossRef]

39) Frare JC, Nicolau RA: Clinical analysis of the effect of laser photobiomodulation $(\mathrm{GaAs}-904 \mathrm{~nm})$ on temporomandibular joint dysfunction. Braz J Phys Ther, 2008, 12: 37-42.

40) Carrasco TG, Mazzetto MO, Mazzetto RG, et al.: Low intensity laser therapy in temporomandibular disorder: a phase II double-blind study. Cranio, 2008, 26: 274-281. [Medline]

41) Manfredini D, Winocur E, Ahlberg J, et al.: Psychosocial impairment in temporomandibular disorders patients. RDC/TMD axis II findings from a multicentre study. J Dent, 2010, 38: 765-772. [Medline] [CrossRef]

42) Türp JC, Motschall E, Schindler HJ, et al.: In patients with temporomandibular disorders, do particular interventions influence oral health-related quality of life? A qualitative systematic review of the literature. Clin Oral Implants Res, 2007, 18: 127-137 [CrossRef]. [Medline]

43) El Hage Y, Politti F, Herpich CM, et al.: Effect of facial massage on static balance in individuals with temporomandibular disorder - a pilot study. Int J Ther Massage Bodyw, 2013, 6: 6-11. [Medline]

44) de Almeida P, Lopes-Martins RA, Tomazoni SS, et al.: Low-level laser therapy improves skeletal muscle performance, decreases skeletal muscle damage and modulates mRNA expression of COX-1 and COX-2 in a dosedependent manner. Photochem Photobiol, 2011, 87: 1159-1163. [Medline] [CrossRef]

45) Pinto MV, Da Costa DA, Rocha LL, et al.: Comparative study of the effects of the Ga-As $(904 \mathrm{~nm}, 150 \mathrm{~mW}$ ) laser and the pulsed ultrasound of $1 \mathrm{MHz}$ in inflammation of tibialis muscle of wistar rats. Braz. Arch Biotechnology (N Y), 2008, 51: 225-230.

46) Goldman JA, Chiapella J, Casey H, et al.: Laser therapy of rheumatoid arthritis. Lasers Surg Med, 1980, 1: 93-101. [Medline] [CrossRef]

47) Conti PC: Low level laser therapy in the treatment of temporomandibular disorders (TMD): a double-blind pilot study. Cranio, 1997, 15: 144-149. [Medline]

48) Pinheiro AL, Cavalcanti ET, Pinheiro TI, et al.: Low-level laser therapy in the management of disorders of the maxillofacial region. J Clin Laser Med Surg, 1997, 15: 181-183. [Medline]

49) Schuhfried M, Korpan V, Silig Y: Helium- Neon laser irradiation: effect on the experimental pain threshold. Lasers Med Sci, 2000, 15: 169-173. [CrossRef] 